\title{
"We Prefer the Friendly Approach and Not the Facility": On the Value of Qualitative Research in Ethiopia
}

\section{Ruth Jackson $^{1^{*}}$}

ABSTRACT

BACKGROUND: Quantitative research is useful for answering 'how many' or 'how much' questions, while qualitative research helps answer 'why' and 'how' questions. Most research about health extension workers (HEWs) has been quantitative and few studies examine the experiences of HEWs themselves. This qualitative study draws attention to the gendered dynamics of human resources for health at the community level.

METHODS: Focus Group Discussions (FGDs) with $14 \mathrm{HEWS}$ (two FGDs in Afar Region and two in Southern Nations Nationality and Peoples Region), and interviews with $45 \mathrm{HEWs}$ from Afar Region, SNNPR and Adwa (Tigray Region) were conducted to identify how gender issues affected their well-being. Questions were designed to explore personal safety, stress, autonomy, self-esteem, family, other social relationships, as we wanted to analyze the extent to which these gendered issues affected HEWs in their day-to-day work.

RESULTS: By employing female HEWs, the Health Extension Program (HEP) has seen substantial gains in 'practical' gender needs by improving women's access to, and utilization of maternal and child health services. Although the HEP has the potential to be gender transformative by providing employment for HEWs, there is limited evidence that it 'strategically' advances women's position. Many HEWs had heavy workloads, received low pay relative to other public sector jobs and lacked opportunity to transfer or upgrade their skills and advance within the health workforce hierarchy.

CONCLUSION: Qualitative research can provide complex descriptions of the social world to better understand what people such as HEWs say and the meanings they give, thus providing explanations for some health problems outside disciplinary boundaries.

\section{INTRODUCTION}

Quantitative research is useful for answering 'how many' or 'how much' questions. For example, we know that an estimated 11,000 Ethiopian women died in childbirth in 2015 (1), and that the percentage of women giving birth in health facilities in rural or urban areas is around $20 \%$ and $79 \%$ respectively (2). In further examples, 
much of the research about health extension workers (HEWs) in Ethiopia has tended to be quantitative such as (3-10):

1. How many HEWs are there? What is the attrition rate?

2. Do health workers including HEWs retain knowledge gained in maternal and newborn health training?

3. How many children did HEWs vaccinate or how many women were referred for antenatal care (ANC)?

4. How many births and maternal deaths were registered?

5. What are HEWs perceptions of facilitators and barriers to institutional delivery?

6. How do HEWs manage their time?

Qualitative research, on the other hand, attempts to answer 'why' and 'how' questions by looking at the meanings of people's lives; representing their views and perspectives; attending to and accounting for real-world conditions; contributing insights from existing or new concepts that might help explain social behavior; and, acknowledging 'the potential relevance of multiple sources of evidence rather than relying on a single source alone' (11). Qualitative researchers 'place the interpretative process at the center of their practice. The interpretative process refers to the way that people interpret and give meaning to events and things' (12). This article uses examples of qualitative research about HEWs as an entry point to encourage students of purely quantitative health services research to consider concepts, tools and outcomes outside their disciplinary boundaries.

In qualitative research about HEWs' relationships with the community and the health sector, Kok et al. (13) found that strong relationships with the community were built on trust and effective communication, while topdown supervision and inadequate training hampered relationships and demotivated HEWs from the health sector side. Gebrehiwot's et al. (14) research with HEWs and midwives shows how the major barriers to institutional delivery are closely connected with the Three Delays Model. Other qualitative research shows that when HEWs call ambulances to transfer women to health centers either before their Expected Due Date or when labour starts at home, more women give birth in health facilities attended by skilled birth attendants (15). HEWs are more likely to call ambulances to refer pregnant and birthing women if they were supported by the Health Development Army, when there was a functioning referral system, when health staff provided respectful care, and when ambulances were available anytime $(16,17)$.

However, there is very little qualitative research that examines the gendered role of HEWs even though the Health Sector Gender Mainstreaming Manual explicitly states that gender equality helps to counter the burden of inequality and the rights of women and girls in 'households, communities, workplaces and health care settings' (18). There are close to 40,000 HEWs with this number projected to reach over 50,000 by 2020 . HEWs account for almost 50 percent of the entire health workforce in Ethiopia (19-21). Most HEWs are females (some males are employed in the emerging regions) because of their key role in improving the health of mothers and newborns. By deliberately recognizing 'women's traditional role as care providers and as health care seekers,' the HEP uses 'a culturally acceptable approach to facilitate access to health services through women health providers to every household' (18).

A qualitative research by Maes et al. (22) examined key features of the Health Extension Program by interviewing district health officials, HEWs and leaders of the Women's Development Army (also known as the Health Development Army or HDA) about payment and empowerment. The goals of the HDA are to reduce mortality, to produce 'model' women who enact healthy behaviours in themselves and others, and to 'empower' 'women to be more autonomous from husbands and more active in developmentoriented work' (22). Both HEWs and district health officials stated that HEW salaries were insufficient to meet basic living costs and that HEWs heavy workload made it difficult to fill vacant positions. Some HEWs seek other 
employment, and others ask to be reassigned to be closer to towns.

\section{METHODS}

This article draws on research from a larger study that trained health extension workers (HEWs) from Afar Region, Kafa Zone (SNNPR), and Adwa Woreda, Tigray Region to interview women about their experiences giving birth in the previous two years (15-17). As HEWs collected data for the larger project and as we interviewed the HEWs about their work, we identified gender issues as being pertinent to their well-being. The aim is to show how qualitative research can build a richer picture of the lives of HEWs in rural Ethiopia.

We conducted a literature review, and additional interviews and focus group discussions (FGDs) to explore how gender considerations interacted with HEWs' roles. Interviews were conducted with 45 HEWs in Afar Region; two locations in Southern Nations, Nationalities, and People's Region (SNNPR): Aleta Wondo Woreda and Kafa Zone; and Adwa Woreda, Tigray Region. Four focus group discussions (FGD) with four to eight HEWs were conducted: one in Aleta Wondo Woreda, one in Kafa Zone and two in Afar Region (one with HEWs and one with women extension workers employed by Afar Pastoralist Development Association or APDA). APDA trains Afar women to teach hygiene, sanitation, nutrition, safe motherhood, HIV prevention, and stopping harmful practices to other Afar women: they do not provide the same services as government HEWs but play a key role in increasing female health-seeking behavior.

Interview and FGD questions were designed to explore how HEWs dealt with issues of personal safety, stress, autonomy, self-esteem, family and other social relationships as we wanted to analyze the extent to which these gendered issues affected HEWs in their day-to-day work. We employed interpreters to assist with interviews or FGDs: in Afar Region (Afarinya); Aleta Wondo Woreda (Amharic); Kafa Zone (Kaffigna); and Adwa Woreda (Tigrinya).

Interview and FGD results were recorded into notebooks and later translated into English by interpreters and transcripts de-identified. Data were entered into Microsoft Word and key themes identified using the Interagency Gender Equality Continuum (GEC) to provide a framework for understanding how to integrate gender into social and behaviour change interventions. The GEC can be used as a planning framework or diagnostic tool by first assessing how well interventions identify, examine and address gender considerations, and then moving interventions along the continuum toward more gender transformative programming and better development outcomes (23-24).

Ethical approval was obtained from the Federal Democratic Republic of Ethiopia Ministry of Science and Technology National Research Ethics Review Committee (Phase 27, No 189) and Deakin University (2013-055). Free and informed consent was obtained for each FGD participant and for all HEW interviews and interviews with other health workers. All the information was kept confidential, and each respondent was given a coded identifier (e.g. Afar HEWs were numbered AHEW1 or FGD1, Kafa HEWs, KHEW1 or KFGD1 and so on).

\section{RESULTS}

This research about the gender dimensions of HEWs' role and experiences, aimed to give voice to the HEWs; to critique some of the assumptions underlying the gender aspects of the Health Extension Program; and, to make recommendations for considering gender issues/mainstreaming gender and HEWs empowerment in the Health Extension Program (25). HEWs are selected by a committee of local community members, representatives from the woreda health office, the capacity building office and the woreda education office. The criteria for selection for rural HEWs was that they must be female, know the local language, be aged over 18 and have completed Grade 10.

HEWs in this study reported that they joined the HEP to help their communities and because they had few other job opportunities. While conducting interviews with women about the services they provided in the main study, HEWs received feedback-some for the first time-about

DOI: http://dx.doi.org/10.4314/ejhs.v28i5.6 
how much their presence and personalized care in the kebeles was appreciated. The focus on maternal, newborn and child health at the kebele level has resulted in significant increases in the percentage of women accessing ANC (from 27\% in 2000 to $62 \%$ in 2016) and Skilled Birth Attendance (from $6 \%$ in 2000 to $28 \%$ in 2016) (2). Many women told HEWs that they were like family members who know their secrets. One HEW reported:

Women prefer coming to see us at the health post rather than the health center because of the physical distance and because the health center asks for too much money. Women say that they are treated better at the health post, as staff are not always kind at the health center. At the health post that they feel that they are telling their secrets to one of their sisters-they can't talk about these things to people they don't know (KHEW4).

Another HEW said:

When I explain to women that they should go to the health center to give birth, that it is a good facility, they say: "we prefer the friendly approach from health extension workers we know, and not to go to the health center where we don't know the staff'" (KHEW4).

Some of the constraints HEWs mentioned were shortages of medical equipment, broken equipment not being replaced, and sporadic supplies of gloves and medicines. Lack of transport to rural kebeles was a major constraint so if HEWs accompanied a woman in an ambulance, they were often expected to walk home. Some HEWs had concerns about their personal safety and mentioned risks related to sexual harassment or sexual assault:

We are fearful of going out. One HEW was abducted and raped (four years ago). There was no solution for this, no justice for the HEW, so due to that we are all fearful (AFGD).

We are concerned about our safety because we are female. In one place where we don't know the language, we ask someone to come with us; we are afraid of robbers and rape. We must walk two hours to reach there. Sometimes crazy men try to kiss us (KHEW6).
As the philosophy underpinning the HEP has been that HEWs come from and serve their own communities, until recently they have not been able to ask for transfer to other health posts. This policy has caused considerable stress and grief for HEWs who were unable to live with their husband and children:

I live $10 \mathrm{kms}$ away from my husband and children. Most HEWs who leave do so because they can't move. Husbands and wives are separated. I love my job. I love my husband and my child. How can I choose between them? (KHEW6).

One HEW got married and her husband works $400 \mathrm{kms}$ away. She works in Dubti and lives in Logyia with her family. Who should visit the other person? In this instance, it is him (AFGD).

One HEW with eight years' experience said: "There is a motto-'No mother should die while giving life'-this motto also works for the health extension workers. We are giving life-but we are not changed-we are dying while giving life" (KFGD). This HEW walked everywhere to visit women in their homes to refer them to health centers for ANC and skilled delivery and to make sure all the children were vaccinated. But she was unable to live with her husband and children who lived in the neighboring woreda.

Many HEWs were unhappy with the lack of career path or opportunities to move into different or higher positions with better working conditions. HEWs wanted more training to improve their knowledge and performance and to progress into positions of higher status and responsibility which attract better salaries and conditions (Level IV):

We feel demoralized when we see our classmates from school who have become engineers, nurses, or those who finished Year 12. We are still here-even those in the classes below us have gone on to university (AFGD).

We cannot work with joy, with happiness now, because there are no follow-up positions, no opportunities to do anything else (AWFGD).

DOI: http://dx.doi.org/10.4314/ejhs.v28i5.6 
Even HEWs who were offered Level IV training were reluctant to leave their family behind as the training was for one year and took place in another part of the region: for example, in Amman (Bench Maji Zone) for the Kafa HEWs or Harar for the Afar HEWs. Two Kafa HEWs stated that they did not plan to continue their work as HEWs beyond the compulsory two years after they upgraded to Level IV because they were still unable to transfer to live with their husband and children.

In contrast, the APDA women's extension workers have a much higher retention rate than HEWs and were committed to staying on:

Being a women's extension worker means you can't leave; no one has left. It's our life...I hope one of my daughters will follow in my footsteps...Now, if I go to any part of Afar...I am taken in as a sister. I get love and respect in the community, as if I was in the compound of my community. Now I can go anywhere in the whole of Afar (WEWFGD).

Many HEWs expressed a desire to leave the HEW role. Reasons for wanting to leave included heavy workload and the nature of duties; needing to walk long distances carrying heavy equipment such as weighing instruments and record-keeping folders; low pay; and lack of opportunity for transfers or career advancement. As one HEW said: "When I decided to become a health extension worker I was happy. Now, because of all the challenges, I don't want to work like before" (AWFGD).

Not one HEW thought that men should be trained to become HEWs. All of them confirmed the Federal Ministry of Health's rationale of selecting women to become HEWs. As one HEW said, "Men do not have patience-the government knows this-that's why they selected women to become HEWs" (KFGD).

\section{DISCUSSION}

Gender roles and relations are changing in Ethiopia, in part, by addressing 'practical' gender needs, by improving conditions for women within their existing socially defined gender roles. The women-to-women approach that underpins the
Health Extension Program is valuable, but it appears to have overshadowed all other gender issues or problems those the service providers (the HEWs) could face. HEWs are female because of their key role in improving the health of mothers and newborns at the community level (18). Thus, the HEWs we met were happy because they ensured mothers and children were vaccinated, that women attended ANC and were referred to health centers to give birth. These achievements are all in line with the goals of the Health Extension Program. Other studies have shown that trust and respect from the community is enhanced when HEWs are supported by the HDA, by the kebele administration and from other health professionals and managers (13).

For the HEWs in this study, some of their practical gender needs were met, including gaining access to a livelihood option where few opportunities existed. Through HEW training, they also gained the practical benefit of knowledge they can personally use in managing their own health and the health of their families. Yet the roles of men and women in development are seen as different by state agents: men's roles (and to a lesser extent, women's) are important to improve agriculture, while women's roles are important for improving population health. Moreover, 'men are seen as a hindrance to women's empowerment in the health sector,' so government and donors are interested in changing men's attitudes and empowering 'women to play bigger, more autonomous roles in households and communitylevel activities' (22).

We found that although there is potential for the Health Extension Program to 'strategically' advance women's position, the research found limited evidence that this is being realized. Addressing strategic gender needs can have more effective and sustainable outcomes for gender equality by strengthening or at least challenging women's position in terms of gender roles and relations. Many HEWs struggled with their heavy workload and some felt they needed to choose between working as a HEW and being able to live with their husband and children. HEWs said that the HEW role was not sought after by young women and that there was a limited career path

DOI: http://dx.doi.org/10.4314/ejhs.v28i5.6 
open to HEWs. Other factors HEWs reported were low salary, inability to transfer to other locations, and poor supervision and support (25). While many of these factors may have been addressed recently with the introduction of a health workers' association and a commitment by the Ministry of Health to upgrade all HEWs to Level IV and to allow transfers (26), as female health workers, HEWs' position at the bottom of the health system hierarchy is one where they have little power, and no opportunity to 'organize and take a seat at the policy table' (27).

The findings should be interpreted with limitations. Although this study was part of a larger project, this aspect of the research took place after the other data collection had been completed. As there was limited time, selection of HEWs for the additional FGD was based on their availability. As the sample size was small we tried to avoid social desirability bias by starting the interviews and FGD by explaining that as there was very little research about the role HEWs so we were interested in their personal stories. We explained that we wanted them to be honest, and that any personal information would remain confidential. Although the outcomes of the study cannot be generalized, we found that the HEWs from three regions had similar stories about their lived experiences, thus improving our understanding of some aspects of HEWs experiences. More research with HEWs with larger samples would improve the transferability of the findings to other settings in Ethiopia.

In conclusion, while quantitative research can quantify people's responses allowing more generalization of the results, qualitative research can help us to better understand those results. According to Kloos et al. (28), health problems appear to be growing more complex and governments are having more difficulty trying to ameliorate them so there is a need for more interdisciplinary research to examine the concepts, tools and outcomes needed to solve health problems. And Maes et al. (22), suggest that ethnography involving participant observation and interviews based on trust, confidentiality and impartiality 'can paint a nuanced picture of how state elites, low-level workers, and peasants cooperate and come into conflict in their varied attempts to improve community health.' For HEWs who play a critical role by referring pregnant and birthing women from rural kebeles to woreda health centers, transforming gender relations and the social norms that perpetuate gender inequalities should address HEWs workload, shortages of supplies, lack of opportunities for transfer, training and advancement.

\section{REEFERENCES}

1. WHO, UNICEF, UNFPA, World Bank Group, United Nations Population Division. Trends in Maternal Mortality: 1990 to 2015. Geneva, Switzerland: World Health Organization, 2015.

2. Central Statistical Agency (CSA) [Ethiopia] and ICF. Ethiopia Demographic and Health Survey 2016: Key Indicators Report. Addis Ababa, Ethiopia, and Rockville, Maryland, USA: CSA and ICF, 2016.

3. Center for National Health Development in Ethiopia, Columbia University. Ethiopia Health Extension Program Evaluation Study, 2007-2010, Volume-II. Health post and HEWs performance Survey. Addis Ababa: Center for National Health Development in Ethiopia, Columbia University, 2011.

4. Center for National Health Development in Ethiopia, Columbia University. Ethiopia Health Extension Program Evaluation Study, 2005-2010, Volume-IV. Support and management of HEP. Addis Ababa, Ethiopia: Center for National Health Development in Ethiopia, Columbia University, 2011.

5. Gobezayehu, AG, Mohammed, H, Dynes, MM, Desta, BF, Barry, D, Aklilu, Y, Tessema, H, Tadesse, L, Mikulich, M, Buffington, ST, Sibley, LM Knowledge and Skills Retention Among Frontline Health Workers: Community Maternal and Newborn Health Training in Rural Ethiopia. J Mid Women's Health 2014:59(s1):S21-S31.

6. Mangham-Jefferies L, Mathewos B, Russell J, 
Bekele A. How do health extension workers in Ethiopia allocate their time? Human Resource Health 2014;12(1):61.

7. Medhanyie A, Spigt M, Dinant G, Blanco R. Knowledge and performance of the Ethiopian health extension workers on antenatal and delivery care: a cross-sectional study. Human Resource Health 2012;10(44).

8. Yitayal M, Berhane Y, Worku A, Kebede Y. Health extension program factors, frequency of household visits and being model households, improved utilization of basic health services in Ethiopia. BMC Health Serv Research 2014;14(1):156.

9. Tilahun, H, Fekadu, B, Abdisa, H, Canavan, M, Linnander, E, Bradley, EH, Berman, P. Ethiopia's health extension workers use of work time on duty: time and motion study. Health Policy Planning 2017; 32(3) 320-328.

10. Yaya, Y, Data, T, Lindtjørn, B. Maternal mortality in rural south Ethiopia: Outcomes of community-based birth registration by health extension workers. PLOS ONE 2015; 10(3) doi10.1371/journal.pone.0119321

11. Yin RK. QUALITATIVE RESEARCH FROM START TO FINISH: SECOND EDITION: New York: Guilford Press; 2016.

12. Liamputtong P, Ezzy D. QUALITATIVE RESEARCH METHODS, SECOND EDITION. Melbourne: Oxford University Press; 2005.

13. Kok M, Kea AZ, Datiko D, Broerse J, Dieleman M, Taegtmeyer $M$, et al. A qualitative assessment of health extension workers' relationships with the community and health sector in Ethiopia: opportunities for enhancing maternal health performance. Human Resource Health 2015;13(1):80.

14. Gebrehiwot T, San Sebastian M, Edin K, Goicolea I. Health workers' perceptions of facilitators of and barriers to institutional delivery in Tigray, Northern Ethiopia. $B M C$ Pregnancy Childbirth 2014;14(1):1-18.

15. Jackson R, Tesfay FH, Gebrehiwot TG, Godefay H. Factors that hinder or enable maternal health strategies to reduce delays in rural and pastoralist areas in Ethiopia. Trop Med Int Health 2017;22(2):148-60.
16. Jackson R, Tesfay F, Godefay H, Gebrehiwot T. Health extension workers' and mothers' attitudes to maternal health service utilization and acceptance in Adwa Woreda, Tigray Region, Ethiopia. PLoS ONE 2016;11(3):e0150747.

17. Jackson R, Hailemariam A. The role of health extension workers in linking pregnant women with health facilities for delivery in rural and pastoralist areas of Ethiopia. Ethiop $J$ Health Sci 2016;26(5):471-478.

18. Federal Democratic Republic of Ethiopia Ministry of Health. Health Sector Gender Mainstreaming Manual. Addis Ababa: Federal Democratic Republic of Ethiopia Ministry of Health, 2013.

19. Africa Health Workforce Observatory. Human Resources for Health Country Profile: Ethiopia. 2010.

20. Feysia B, Herbst C, Lemma W, Soucat A, Zhao F, Kedir N, et al. The Health Workforce in Ethiopia: Addressing the remaining challenges. Washington DC: The World Bank, 2012.

21. Lavallée R, Hanvoravongchai P, Gupta N. Use of population census data for gender analysis of the health workforce. In: Handbook on Monitoring and Evaluation of Human Resources for Health with special applications for low- and middle-income countries [Internet]. World Health Organization, The World Bank, USAID. 2009. Available from: http://whqlibdoc.who.int/publications/2009/97 89241547703 eng.pdf.

22. Maes, K, Closser, S, Vorel, E, Tesfaye, Y. Using community health workers: Discipline and Hierarchy in Ethiopia's Women's Development Army. Annals Anth Prac 2015; 39(1):42-57.

23. Interagency Gender Working Group. Gender Integration Continuum Categories. 2014. < http://www.igwg.org/igwg_media/Training/G endrContinuumCategories.pdf>.

24. Kraft, JM, Wilkins, KG, Morales, GJ, Widyono, M, Middlestadt, SE. An Evidence Review of Gender-Integrated Interventions in Reproductive and Maternal-Child Health. $J$ Health Comm 2014;19(sup1):122-141. 
25. Jackson R, Kilsby D. "We are dying while giving life": Gender and the role of Health Extension Workers in rural Ethiopia. Geelong, Australia: Report to the Federal Ministry of Health Women and Youth Affairs Directorate and UN agencies in Ethiopia, 2015.

26. Federal Ministry of Health. Health Sector Transformation Plan 1 Version 1 Annual Performance Report EFY 2008 (2015/16). 2015/16.

27. Maes K, Closser S, Vorel E, Tesfaye Y. A
Women's Development Army: Narratives of Community Health Worker Investment and Empowerment in Rural Ethiopia. Studies Comp Int Dev 2015;50(4):455-78.

28. Kloos H, Haile Mariam D, Kaba M. Interdisciplinary and Inter-institutional Research Published in the Ethiop J Health Dev $25^{\text {th }}$ Annual Conference and Silver Jubilee Anniversary of Ethiopian Public Health Association; 20-22 February; African Union 2014. 